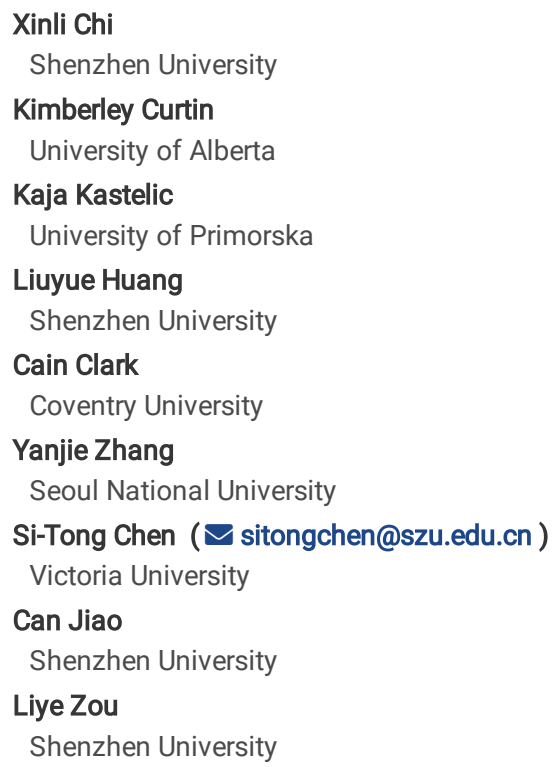

\title{
Muscle-Strengthening Exercise and Depression in Chinese Young Adults
}




\section{Abstract}

Studies based on western population have indicated that muscle-strengthening exercise (MSE) has positive roles against mental disorders, but little is known about that in Chinese adults. This study, thus, aimed to explore the association between MSE and depression in Chinese university students (aged 18-24 years). A convenient sample of 1794 university students (mean age: 20.67 years) were recruited into this study. A self-reported questionnaire was used to collect information on participants' sociodemographic information (e.g., sex, body mass index) and MSE. Physical activity and sleep were measured using the International Physical Activity Questionnaire-Short Form and Pittsburgh Sleep Quality Index. Study participants' depression severity was assessed using the Patient Health Questionnaire-9. A multilevel linear regression was performed to examine the association between MSE and depression. Only $24.87 \%$ of study participants met the World Health Organization MSE guidelines of more than 2 days/week. The mean score of depression was 6.80 ( \pm 5.19 ). More days for MSE (0-7 days) was negatively associated with depression (beta $=-0.17,95 \% \mathrm{Cl}:-0.31--0.03, p=0.015)$. Students who did not meet MSE guidelines were more likely to have higher risks for depression (beta $=0.63,95 \% \mathrm{Cl}$ : $0.09-0.19, p=0.027$ ). The results indicate that engaging in MSE could be related to decreased depression in Chinese young adults. Interventions aiming at reducing depression could incorporate MSE as a strategic component.

\section{Background}

Depression is characterized by sadness, loss of interest or pleasure, feelings of guilt or low self-worth, disturbed sleep and/or appetite, feelings of tiredness, and poor concentration [1, 2]. Depression is one of the leading mental health problems in the global population [2, 3] with more than 264 million people living with depression around the world [2]. As a common mental health disorder, depression has adverse negative effects on physical health and overall mental wellbeing [4-6], often contributing to deaths by suicide [2]. More recent data shows that depression is the third cause of global disease burden (first in developed countries) and is expected to become the first cause of disease burden worldwide by 2030 , with related suicide rates more likely to increase [7]. According to the World Health Organization (WHO), depression has become the second largest killer of humans after cancer [2]. Many young adults (1825 years) have been diagnosed with depressive symptoms across the world; one of the 10 diseases leading to death in this age group [8-10]. Several multidimensional factors interact to increase the vulnerability of young adults to depression [11, 12]. The prevalence of depression in Chinese university students (young adults) is of great concern $[13,14]$. Depression as an individual and public health issue has attracted a large amount of attention from policymakers, scholars, and practitioners. For example, in September 2020, the Chinese General Office of the National Health Commission issued the "Working Plan for Exploring Special Services for the Prevention and Treatment of Depression". The policy requires depression screening to be included in student health examination at universities.

In light of the increasing prevalence and health burden of depression, researchers are encouraged to identify various risk factors of depression [15, 16], resulting in more effective interventions aiming at reducing depression. Several studies have considered sufficient physical activity (PA) as a protective factor against depression in young adults [17-20]. However, those studies focused on overall volume of PA instead of one specific modality of PA, which may inhibit more nuanced understanding the role of PA in preventing depression. Recently, some research has investigated association between muscle-strengthening exercise (MSE) and depression because of MSE's emerging role in promoting health [21]. For example, Bennie et al. [22] recently published a cross-sectional study of a nationally representative sample of German adults, finding that MSE might be a protective factor against depression. Based on the epidemiological evidence, it is likely that MSE can play a positive role in preventing depression in adults. However, more studies are encouraged to replicate or negate evidence regarding associations between MSE and mental health indicators, especially in varying ethnic and age groups [21].

Although previous research is promising in this area, several important limitations should be noted. One major limitation is that most previous studies were based on Western populations while, to our knowledge, little is known about the roles of MSE on depression in Chinese populations. Another study limitation involves in a lack of measuring or accounting for confounders when assessing the association between MSE and depression. Specifically, two studies by Bennie et al. [22, 23] omitted two important confounders, such as sedentary behavior and sleep duration, that have been recognized as correlates of depression in young adults. Sleep and sedentary behaviour are important considerations that can contribute to understanding potential moderators of the relationship between MSE and depression [24].

The present study aimed to address the gaps in the literature and explore the association between MSE and depression in young adults (i.e., a sample of Chinese university students) in China. This research provides a basis for identifying similarities with previous research as well as designing effective interventions and informing policies for depression prevention in Chinese young adults.

\section{Methods}

\subsection{Study design and participants}

Our study originated from a longitudinal study survey (ongoing) to assess the impacts of the coronavirus disease (COVID-19) outbreak on Chinese university students' mental health [25]. We intended to conduct at least 4 consecutive surveys (starting February 2020 and performing the surveys at a three-month intervals) among students from 10 universities in southern China. In wave 3, we assessed MSE using the survey. The survey was sent to study participants who agreed to join in wave 3 (provide consent in wave 2). In wave 3, 1159 study participants responded to the questionnaire. To increase the sample size, we invited additional study participants to complete the same measurements. In brief, 714 participants responded and submitted the questionnaire. Both of the surveys were conducted from August $21-31,2020$. Of all the study participants ( $N=1873), 1793$ study participants provided valid data pertaining to all the variables included in this study (response rate $=95.73 \%$ ). All the study participants provided informed consent to participate in this study prior to data collection

\subsection{Procedure and data collection}


The survey was conducted online for both convenience and safety reasons in light of the COVID-19 outbreak. Over a period of 10 days, students were invited to participate in the survey (hosted at wenjuanxing [wjx.cn], Ranxing Information and Tech Company, Changsha, China) via Tencent's QQ, WeChat, Weibo, and college-related websites (e.g., university association websites and bulletin board system forums). The survey took approximately 15 minutes to complete, and participants were given $10 \mathrm{RMB}$ (Chinese currency) via online payment (equivalent to $1.5 \mathrm{U}$.S. dollars at the current rate). Recruitment and data collection procedures were approved by the Human Research Ethics Committee (No:2020005) of Shenzhen University.

\subsection{Measures}

\section{(1) Muscle-strengthening exercise (MSE)}

Each study participant was asked to report engagement in MSE by responding to the question "how many days did you do MSE over the past week?" In this context, MSE was defined as "activities involving major muscle groups [26], like push-ups, weightlifting, curl-ups or pull-ups". Responses for study participants ranged from 0 to 7 days. Similar questions had been used in studies based on US [27-29] and Australian [30-32] as well as Chinese [33] populations, which showed acceptable reliability. In accordance with WHO and consistent with past studies (two or more days for MSE as a cut-off) [26], participants were classified as meeting the MSE guidelines if they reported having participated in MSE two or more times per week. In the statistical analyses, the variable of MSE days was treated as continuous while the variable of meeting MSE guidelines or not was treated as binary outcome.

\section{(2) Depression (PHQ-9)}

Participants' depressive symptoms were assessed by the Patient Health Questionnaire-9 consisting of 9 items (PHQ-9) assessing self-report of major depressive symptoms (e.g., little interest and bad feeling from the survey) relative to the last two weeks where participants responded from $0=$ not at all to $3=$ almost every day [34]. A previous study found that the reliability and validity of the PHQ-9 (Chinese version) in university students was acceptable [35], and can be used in epidemiological surveys. In our analyses, the scores of PHQ-9 were treated as a continuous variable.

\section{(3) Socio-demographic variables and other control variables}

Based on previously published studies [22, 23], the variables of sex (male or female), age (years), body mass index (BMl; calculated by self-reported height [cm] and weight $[\mathrm{kg}]$ ), siblings (single or two or more), residence (urban or rural), family structure (full, divorced or other), parental educational level (middle school or below, high school, college or university, master or above), estimated number of close friends (none, 1-2, 3-5, 6 or more), perceived family affluence and physical activity behavior were assessed. Perceived family affluence was assessed by a scale (from 0 to 10) developed by Nancy et al. [36], which higher scores indicate more perceived family affluence.

Physical activity behavior was assessed by the International Physical Activity Questionnaire-short form (IPAQ-SF), its reliability and validity has been reported in Chinese populations [37], indicating the IPAQ-SF was acceptable to capture Chinese adults' physical activity and sedentary behavior. In brief, study participants were required to recall their physical activity (e.g., vigorous, moderate and light) and sedentary behavior (e.g., sitting during leisure time and transportation time) over the past 7 days. Minutes of physical activity and sedentary time per week were calculated based on the published guidelines by the IPAQ expert group [38]. Study participants' sleep duration (hours) was assessed by Pittsburgh Sleep Quality Index (PSQI) that has been validated in Chinese populations [39]. In the statistical analyses, age, BMI, perceived family affluence, physical activity, sedentary behavior and sleep duration were treated as continuous variables while other potential confounding/ moderating variables were included as categorical variables.

\subsection{Statistical analyses}

All the statistical analyses were conducted using SPSS version 25.0. Descriptive statistics calculated were frequency and percentage (\%) of categorical variables (e.g., sex, residence, days for MSE) as well as mean and standard deviation of continuous variables (e.g., age, BMI). Pearson's chi square was used to examine sex differences across all the categorical variables and student t test was used to examine sex differences across all the continuous variables. Pearson correlation coefficients were calculated to determine bivariate associations among study variables. A multilevel linear model (also known as hierarchical linear model; HLM) was used to estimate the association between MSE and depression. This technique takes into account the dependency of observations within multiple clusters (in this case, individual characteristics were nested within city). A multilevel linear regression controls for confounding variables on the micro-level (individual), as well as the macro-level (cities). Based on our data structure in this study, we fitted our data as a two-level structure (level 2: city; level 1: individual), which then uses the Linear Mixed Models function with Restricted Maximum Likelihood Estimation (REML) to examine the associations between MSE and depression. To thoroughly explore the association between MSE and depression, two models were established (model 1: MSE days as independent variable; model 2: MSE guidelines as independent variable) and controlled for all the sociodemographic and control variables. Adjusted beta estimates with corresponding $95 \%$ confidence intervals $(95 \% \mathrm{Cl})$ are described in the results. Statistical significance was defined as $p<0.05$ (two sided).

\section{Results}

Socio-demographic characteristics of the study sample and variables are outlined in Table 1. In Total, 1793 participants (63.58\% female) were included in this study, the average of BMI was $20.27 \pm 2.86 \mathrm{~kg} / \mathrm{m}^{2} .34 .18 \%$ of participants were only-child, and the percentage of participants living in urban area was $69.21 \%$. Education level of most of participants' parents were high school or below (M: 82.48\%, F: 89.18\%). 52.2\% of participants reported that they have 3-5 friends. In total, participants accumulated time spent in physical activity $126.98 \pm 120.98 \mathrm{~min} /$ week, sedentary time was $384.53 \pm 222.20 \mathrm{~min} /$ day, and sleep was $443.57 \pm 91.52 \mathrm{~min} /$ day. Moreover, $72.6 \%$ of respondents reported zero days of MSE per week, and the proportions in male and female were $58.04 \%$ and $80.09 \%$, respectively. Overall, $24.8 \%$ of respondents met the MSE guidelines, and the percentage of meeting guidelines in males was more than twice that of the females. In addition, the mean scores of depression in females $(7.24 \pm 5.17)$ was significantly higher that in males $(6.04 \pm 5.13)$. 
Table 2 and Table 3 show the bivariate correlation coefficients among the variables included in this study. Significant relationships were found between depression and MSE days $(r=-0.11, p<0.001)$, and depression and MSE guidelines $(r=-0.11, \mathrm{p}<0.001)$. Multilevel regression models were estimated to determine the association between MSE days and depression (Table 4). In total, a negative relationship between $\mathrm{MSE}$ days $(\beta=-0.17,95 \% \mathrm{Cl}=-0.31$ to -0.03 ) and depression was found. The relationship between meeting MSE guidelines and depression can be found in Table 5. We found a positive relationship between not meeting MSE guidelines $(\beta=0.63,95 \% \mathrm{Cl}=0.07$ to 1.19$)$ and depression compared to meeting the MSE guidelines.

\section{Discussion}

The purpose of this research was to examine the associations between MSE and depression among Chinese young adults while accounting for important third variables such as sleep and sedentary behavior. We found that about a quarter (24.87\%) of Chinese young adults (university students) engaged in at least 2 days of MSE per week. Importantly, more days spent engaging in in MSE or meeting the MSE guidelines were significantly negatively related to depression severity (assessed by PHQ-9). To our knowledge, this is the first study to investigate the prevalence of MSE and its potentially protective role in preventing depression among Chinese young adults, which can advance understandings of mental well-being promotion.

Although MSE has been an imperative component of the well-recognized PA guidelines by the World Health Organization and other national public health sectors (e.g., America and Canada), research focusing on MSE and mental health benefits in various populations remains scarce [21]. This deficiency is a barrier to better understanding physical activity in a way that is comprehensive and inclusive of various populations. The prevalence of meeting the MSE guidelines in our sample is lower ( $24.87 \%$ vs $28.50 \%$ ) compared with one previously published study consisting of adults (from Hubei, China) over 30 years of age [33]. This small discrepancy may be owing to different sample characteristics, such as age, and survey time (e.g., spring, summer). When evaluating the level of MSE in Chinese young adults compared with results based on Western (e.g., America, Australia) study samples, the prevalence of meeting MSE guidelines is generally lower for Chinese samples. For example, Bennie et al. [31] found that $29.2 \%$ of Australian adults aged $18-24$ years complied with the MSE guidelines. In the US, a trend analysis on data from 2011 to 2017 indicated that over $40 \%$ of adults of $18-24$ years met the MSE guidelines regardless of survey year [29]. Taken together, the prevalence of meeting the MSE guidelines among Chinese young adults is lower compared to Western samples, pointing to the importance of intervention in young adults in order to encourage the development of lifelong healthy behaviors in this population [40-45].

Regardless of how we measured MSE in our study (e.g., days or meeting the guidelines), more days of participations in MSE or meeting the guidelines were independently related to lower risks for depression in Chinese young adults. In other words, participations in MSE could be a protective factor against depression. This research finding is consistent with prior research by Jason et al. [22, 23]. Specifically, one study based on German adults aged over 18 years $(N=23,635)$ indicated that increases in MSE would be a beneficially preventive approach to treating depression. Researchers have offered some explanations as to the mechanisms that may help explain MSE's role in decreasing depression severity or symptoms. First, more engagements in MSE can increase muscle strength that has been viewed as a health indicator and component of fitness, which improves individuals' physical function and quality of life [46-48] resulting in decreased depression. Another mechanism examined are myokines produced by MSE that may act as a biological inhibitor against depression [49]. In addition to these more biological mechanisms, as a form of PA, MSE could change individual psychosocial (e.g., self-esteem) and neurobiological (e.g., cerebral blood flow) factors that may both lower depression in adults [50]. However, the mechanism associating MSE and depression should be further clarified in future research. Importantly, because our study adopted a cross sectional design, it is unreasonable to draw conclusions related to causality. Longitudinal or experimental trials to confirm the association between MSE and depression among young adults should be conducted. Altogether, this study suggests that MSE is likely a beneficial factor against depression among Chinese young adults.

Our research findings foster some important practical implications and future research recommendations to inform depression prevention. MSE is a feasible and efficient approach to preventing depression in Chinese young adults. MSE is one form of physical activity that needs few environmental supports (e.g., equipment, playgrounds). For example, individuals can conduct MSE without any equipment or instruments or perform MSE in a small space. The restrictions put in place to prevent the spread of COVID-19 in many countries, such as closing indoor gym spaces, is a testament to the versatility of MSE which many have continued or taken up in their homes. This kind of physical activity has its own merits regarding accessibility over other forms of physical activity, like swimming (need a pool) or ball sports (need balls or mates). Importantly, little is known about correlates/determinants of MSE in Chinese young adults [33] which is a critical component when generating campaigns to encourage young adults to conduct MSE.. Future research should examine and identify components of effective interventions to promote MSE in this population.

A major strength of this study is that we used a large sample to augment evidence on the association between MSE and depression among Chines young adults, and contributed to the evidence base for depression prevention/treatment in Chinese young adults. Another strength is that our study controlled for more variables compared with previous studies, including family-related factors, socioeconomic parameters and behavioral variables (e.g., sedentary behavior and sleep duration). However, some inherent study limitations should be mentioned. The cross-sectional study design is one limitation, which cannot fully answer the cause-and-effect association between MSE and depression. The second limitation is the use of self-reported questionnaires, which may result in recall bias. Our study sample was mainly from southern provinces in China and the generalizability of research findings into wider regions should be approached with caution. The final limitation concerns measurement, which the questionnaire to assess PA (IPAQ) did not require study participants to distinguish moderate to vigorous physical activity and MSE. This implies that IPAQ may capture MSE to some extent. However, the correlation coefficient between moderate to vigorous physical activity and MSE was 0.28 (weak correlation), indicating they are likely not measuring the same thing. Future studies should explicitly distinguish these physical activity types.

\section{Conclusions}

This study is the first to assess the prevalence of MSE and its association with depression in Chinese young adults. Only about a quarter of Chinese young adults met the MSE guidelines (more than 2 days per week). We found that more engagement in MSE may help protect against depression. Future studies are 
encouraged to confirm or negate these research findings using more improved study designs (e.g., follow-up studies or experimental studies). Despite this, our study provides preliminary evidence for depression prevention in Chinese young adults.

\section{Declarations}

-Ethics approval and consent to participate

The administration committees of the surveyed colleges and universities approved the study and data collection, as did the Human Research Ethics Committee of Shenzhen University.

All students in the selected classes were invited to participate in this study $(N=1,200)$, and students who agreed to participate signed consent forms before the questionnaire was administered.

-Consent to publish

Not applicable

-Availability of data and materials

The datasets used and/or analyzed during the current study are available from the first author on reasonable request.

-Competing interests

The authors declare that they have no competing interests.

-Funding

This research was funded by National Social Science Foundation, grant number 16CSH049; Shenzhen Philosophy and Social science Foundation, grant number SZ2018C001; Key Research Projects of Colleges and Universities in Guangdong Province, grant number 2018WZXDM015;Shenzhen Basic Research Grant, 2019SHIBS0003

\section{-Author contributions}

Study design: Xinli Chi and Si-Tong Chen.

Data collection: Xinli Chi, Liuyue Huang, Yanjie Zhang and Can Jiao

Data analysis: Xinli Chi, Liuyue Huang and Si-Tong Chen.

Manuscript draft: Xinli Chi and Si-Tong Chen.

Critical revision: Kimberley Curtin, Kaja Kastelic, Cain Clark, Liye Zou

-Acknowledgement

The authors appreciate all the study participants who responded to this survey

\section{References}

1. What Is Depression? Available online: https://www.psychiatry.org/ patients-families/depression/what-is-depression (accessed on 11 December 2019).

2. https://www.who.int/news-room/fact-sheets/detail/depression

3. Wang PS, Aguilar-Gaxiola S, Alonso J, Angermeyer MC, Borges G, Bromet EJ, Bruffaerts R, De Girolamo G, De Graaf R, Gureje 0: Use of mental health services for anxiety, mood, and substance disorders in 17 countries in the WHO world mental health surveys. The Lancet 2007, 370(9590):841-850.

4. Ribeiro, Jessica D, Huang, Xieyining, Fox, Kathryn R, Franklin, Joseph C: Depression and hopelessness as risk factors for suicide ideation, attempts and death: meta-analysis of longitudinal studies. British Journal of Psychiatry 2018.

5. Wit LD, Luppino F, Straten AV, Penninx B, Cuijpers P: Depression and obesity: a meta-analysis of community-based studies. Psychiatry Res 2010, 178(2):230-235.

6. Reiche EMV, Nunes SOV, Morimoto HK: Stress, depression, the immune system, and cancer. 2004.

7. James SL, Abate D, Abate KH, Abay SM, Abbafati C, Abbasi N, Abbastabar H, Abd-Allah F, Abdela J, Abdelalim A et al: Global, regional, and national incidence, prevalence, and years lived with disability for 354 diseases and injuries for 195 countries and territories, 1990\&\#x2013;2017: a systematic analysis for the Global Burden of Disease Study 2017. The Lancet 2018, 392(10159):1789-1858.

8. Ibrahim AK, Kelly SJ, Adams CE, Glazebrook C: A systematic review of studies of depression prevalence in university students. Journal of Psychiatric Research 2013, 47(3):391-400.

9. Simon GE, Rutter CM, Peterson D, Oliver M, Whiteside U, Operskalski B, Ludman EJ: Does Response on the PHQ-9 Depression Questionnaire Predict Subsequent Suicide Attempt or Suicide Death? Psychiatric Services 2013, 64(12):1195-1202. 
10. Vandivort DS, Locke BZ: Suicide Ideation: Its Relation to Depression, Suicide and Suicide Attempt. Suicide \& Life-threatening Behavior 1979, 9(4).

11. Lopresti AL, Hood SD, Drummond PD: A review of lifestyle factors that contribute to important pathways associated with major depression: Diet, sleep and exercise. Journal of Affective Disorders 2013, 148(1):12-27.

12. Korten NCM, Comijs HC, Lamers F, Penninx BWJH: Early and late onset depression in young and middle aged adults: differential symptomatology, characteristics and risk factors? Journal of Affective Disorders 2012, 138(3):259-267.

13. Chen L, Wang L, Qiu X, Yang X, Qiao Z, Yang Y, Liang Y: Depression among Chinese University Students: Prevalence and Socio-Demographic Correlates. PloS one 2013, 8:e58379.

14. Lei X-Y, Xiao L-M, Liu Y-N, Li Y-M: Prevalence of Depression among Chinese University Students: A Meta-Analysis. PLOS ONE 2016, 11:e0153454.

15. Pedersen G, Zajkowska Z, Kieling C, Gautam K, Mondelli V, Fisher H, Swartz J, Adewuya A, Karmacharya R, Kohrt B: Protocol for a systematic review of the development of depression among adolescents and young adults: psychological, biological, and contextual perspectives around the world. Systematic Reviews 2019, 8.

16. Correia ÉM, Bento T, Rodrigues F, Cid L, Vitorino A, Teixeira DS, Monteiro D: What Is the Recommended Dose of Physical Activity in the Treatment of Depression in Adults? A Protocol for a Systematic Review. Sustainability 2020, 12(14).

17. Rebar AL, Stanton R, Geard D, Short C, Duncan MJ, Vandelanotte C: A meta-meta-analysis of the effect of physical activity on depression and anxiety in non-clinical adult populations. Health Psychology Review 2015, 9(3):366-378.

18. Brunet J, Sabiston CM, Chaiton M, Barnett TA, O'Loughlin E, Low NC, O'Loughlin JL: The association between past and current physical activity and depressive symptoms in young adults: a 10-year prospective study. Ann Epidemio/ 2013, 23.

19. McPhie ML, Rawana JS: The effect of physical activity on depression in adolescence and emerging adulthood: A growth-curve analysis. Journal of Adolescence 2015, 40:83-92.

20. Bailey AP, Hetrick SE, Rosenbaum S, Purcell R, Parker AG: Treating depression with physical activity in adolescents and young adults: a systematic review and meta-analysis of randomised controlled trials. Psychological Medicine 2018, 48(7):1068-1083.

21. Bennie J, Shakespear-Druery J, De Cocker K: Muscle-strengthening Exercise Epidemiology: a New Frontier in Chronic Disease Prevention. Sports Medicine Open 2020, 6.

22. Bennie JA, Teychenne M, Tittlbach S: Muscle-strengthening exercise and depressive symptom severity among a nationally representative sample of 23,635 german adults. Journal of Affective Disorders 2020, 266:282-287.

23. Bennie JA, De Cocker K, Biddle SJH, Teychenne MJ: Joint and dose-dependent associations between aerobic and muscle-strengthening activity with depression: A cross-sectional study of 1.48 million adults between 2011 and 2017. Depression and anxiety 2020, 37(2):166-178.

24. Wu X, Tao S, Zhang Y, Zhang S, Tao F: Low Physical Activity and High Screen Time Can Increase the Risks of Mental Health Problems and Poor Sleep Quality among Chinese College Students. PLOS ONE 2015, 10(3):e0119607.

25. Chi X, Becker B, Yu Q, Willeit P, Jiao C, Huang L, Hossain MM, Grabovac I, Yeung A, Lin J et al: Prevalence and Psychosocial Correlates of Mental Health Outcomes Among Chinese College Students During the Coronavirus Disease (COVID-19) Pandemic. Frontiers in Psychiatry 2020, 11(803).

26. Global recommendations on physical activity for health [https://apps.who.int/iris/bitstream/handle/10665/44399/9789241599979_eng.pdf? sequence=1\&isAllowed=y]

27. Loustalot F, Carlson SA, Kruger J, Buchner DM, Fulton JE: Muscle-Strengthening Activities and Participation Among Adults in the United States. Research Quarterly for Exercise and Sport 2013, 84(1):30-38.

28. Harris CD, Watson KB, Carlson SA, Fulton JE, Dorn JM, Elam-Evans L: Adult participation in aerobic and muscle-strengthening physical activities-United States, 2011. MMWR Morbidity and mortality weekly report 2013, 62(17):326.

29. Bennie JA, Kolbe-Alexander T, Seghers J, Biddle SJH, Cocker KD: Trends in Muscle-Strengthening Exercise Among Nationally Representative Samples of United States Adults Between 2011 and 2017. 2020, 17(5):512.

30. Freeston J, Gale J, Mavros Y, Bennie J, Pedisic Z, Bauman A, Stamatakis E: Associations between multiple indicators of socio-economic status and muscle-strengthening activity participation in a nationally representative population sample of Australian adults. Preventive Medicine 2017:S0091743517302244.

31. Bennie JA, Pedisic Z, van Uffelen JGZ, Gale J, Banting LK, Vergeer I, Stamatakis E, Bauman AE, Biddle SJH: The descriptive epidemiology of total physical activity, muscle-strengthening exercises and sedentary behaviour among Australian adults - results from the National Nutrition and Physical Activity Survey. Bmc Public Health 2016, 16.

32. Bennie JA, Pedisic Z, van Uffelen JGZ, Charity MJ, Harvey JT, Banting LK, Vergeer I, Biddle SJH, Eime RM: Pumping Iron in Australia: Prevalence, Trends and Sociodemographic Correlates of Muscle Strengthening Activity Participation from a National Sample of 195,926 Adults. PLOS ONE 2016, 11(4):e0153225.

33. Lin Y, Yan J: Muscle-Strengthening Activities and Sociodemographic Correlates among Adults: Findings from Samples in Mainland China. International Journal of Environmental Research and Public Health 2020, 17(7):2266.

34. Kroenke K, Spitzer RL, Williams JB: The PHQ-9: validity of a brief depression severity measure. J Gen Intern Med 2001, 16(9):606-613.

35. Du N, Yu K, Ye Y, Chen S: Validity study of Patient Health Questionnaire-9 items for Internet screening in depression among Chinese university students. Asia-Pacific Psychiatry 2017, 9(3):e12266.

36. Adler NE, Epel ES, Castellazzo G, Ickovics JR: Relationship of subjective and objective social status with psychological and physiological functioning: Preliminary data in healthy, White women. Health Psychology 2000, 19(6):586-592. 
37. Macfarlane DJ, Lee CCY, Ho EYK, Chan KL, Chan DTS: Reliability and validity of the Chinese version of IPAQ (short, last 7 days). Journal of Science and Medicine in Sport 2007, 10(1):45-51.

38. Expert Working Grp Consensus P: Guidelines for Data Processing and Analysis of the International Physical Activity Questionnaire (IPAQ) In.; 2005.

39. Guo S, Sun W, Liu C, Wu S: Structural Validity of the Pittsburgh Sleep Quality Index in Chinese Undergraduate Students. Frontiers in Psychology 2016, 7(1126).

40. Bennie JA, De Cocker K, Pavey T, Stamatakis E, Biddle SJH, Ding D: Muscle Strengthening, Aerobic Exercise, and Obesity: A Pooled Analysis of 1.7 Million US Adults. Obesity (Silver Spring) 2019.

41. Bennie JA, Lee D-c, Khan A, Wiesner GH, Bauman AE, Stamatakis E, Biddle SJH: Muscle-Strengthening Exercise Among 397,423 U.S. Adults: Prevalence, Correlates, and Associations With Health Conditions. American Journal of Preventive Medicine 2018, 55(6):864-874.

42. Lesinski M, Herz M, Schmelcher A, Granacher U: Effects of Resistance Training on Physical Fitness in Healthy Children and Adolescents: An Umbrella Review. Sports Med 2020.

43. Carneiro L, Afonso J, Ramirez-Campillo R, Murawska-Ciałowciz E, Marques A, Clemente FM: The Effects of Exclusively Resistance Training-Based Supervised Programs in People with Depression: A Systematic Review and Meta-Analysis of Randomized Controlled Trials. International Journal of Environmental Research and Public Health 2020, 17(18):6715.

44. Westcott WL: Resistance Training is Medicine: Effects of Strength Training on Health. Current Sports Medicine Reports 2012, 11(4):209-216.

45. Winett RA, Carpinelli RN: Potential health-related benefits of resistance training. Preventive medicine 2001, 33(5):503-513.

46. Gerber M, Lindwall M, Lindegård A, Börjesson M, Jonsdottir IH: Cardiorespiratory fitness protects against stress-related symptoms of bumout and depression. Patient education and counseling 2013, 93(1):146-152.

47. Gerber M, Pühse U: Do exercise and fitness protect against stress-induced health complaints? A review of the literature. Scandinavian journal of public health 2009, 37(8):801-819.

48. Mikkelsen K, Stojanovska L, Polenakovic M, Bosevski M, Apostolopoulos V: Exercise and mental health. Maturitas 2017, 106:48-56.

49. Köhler CA, Freitas TH, Maes M, de Andrade NQ, Liu CS, Fernandes BS, Stubbs B, Solmi M, Veronese N, Herrmann N et al: Peripheral cytokine and chemokine alterations in depression: a meta-analysis of 82 studies. Acta Psychiatrica Scandinavica 2017, 135(5):373-387.

50. Kandola A, Ashdown-Franks G, Hendrikse J, Sabiston CM, Stubbs B: Physical activity and depression: Towards understanding the antidepressant mechanisms of physical activity. Neuroscience \& Biobehavioral Reviews 2019, 107:525-539.

\section{Tables}


Table 1

Sample characteristics of this study.

\begin{tabular}{|c|c|c|c|c|c|c|c|c|}
\hline & & \multicolumn{2}{|l|}{ Total } & \multicolumn{2}{|c|}{ Male } & \multicolumn{2}{|c|}{ Female } & \multirow[t]{2}{*}{$p$ for sex difference } \\
\hline & & $\mathbf{N}$ & $\%$ & $\mathbf{n}$ & $\%$ & $\mathbf{n}$ & $\%$ & \\
\hline Sex & & 1793 & 100 & 653 & 36.42 & 1140 & 63.58 & - \\
\hline Age (mean \pm SD) [years] & & \multicolumn{2}{|c|}{$20.67 \pm 1.61$} & \multicolumn{2}{|c|}{$20.75 \pm 1.63$} & \multicolumn{2}{|c|}{$20.63 \pm 1.60$} & 0.110 \\
\hline $\mathrm{BMI}($ mean $\pm \mathrm{SD})\left[\mathrm{kg} / \mathrm{m}^{2}\right]$ & & \multicolumn{2}{|c|}{$20.27 \pm 2.86$} & \multicolumn{2}{|c|}{$21.44 \pm 3.12$} & \multicolumn{2}{|c|}{$19.60 \pm 2.46$} & 0.000 \\
\hline \multicolumn{9}{|l|}{ Siblings } \\
\hline & Single & 613 & 34.18 & 277 & 42.42 & 336 & 29.47 & \multirow[t]{2}{*}{0.000} \\
\hline & Two or more & 1180 & 65.81 & 376 & 57.58 & 804 & 70.53 & \\
\hline \multicolumn{9}{|l|}{ Residence } \\
\hline & Urban & 1241 & 69.21 & 430 & 65.85 & 811 & 71.14 & \multirow[t]{2}{*}{0.020} \\
\hline & Rural & 552 & 30.79 & 223 & 34.15 & 329 & 28.86 & \\
\hline \multicolumn{9}{|l|}{ Family structure } \\
\hline & Full & 1261 & 90.41 & 593 & 90.81 & 1028 & 90.18 & 0.600 \\
\hline & Divorced & 109 & 6.08 & 39 & 5.97 & 70 & 6.14 & \\
\hline & Other & 63 & 3.51 & 21 & 3.22 & 42 & 3.7 & \\
\hline $\begin{array}{l}\text { Perceived family affluence } \\
\text { (mean } \pm \text { SD) }\end{array}$ & & \multicolumn{2}{|c|}{$5.71 \pm 1.64$} & \multicolumn{2}{|c|}{$5.46 \pm 1.69$} & \multicolumn{2}{|c|}{$5.86 \pm 1.59$} & 0.000 \\
\hline \multicolumn{9}{|l|}{ Father education level } \\
\hline & Middle school or below & 867 & 48.35 & 328 & 50.23 & 539 & 47.29 & \multirow[t]{4}{*}{0.291} \\
\hline & High school & 612 & 34.13 & 221 & 33.84 & 391 & 34.30 & \\
\hline & College or university & 250 & 13.94 & 76 & 11.64 & 174 & 15.26 & \\
\hline & Master or above & 64 & 3.57 & 28 & 4.29 & 36 & 3.16 & \\
\hline \multicolumn{9}{|l|}{ Mother education level } \\
\hline & Middle school or below & 1055 & 58.84 & 403 & 61.72 & 652 & 57.19 & \multirow[t]{4}{*}{0.245} \\
\hline & High school & 544 & 30.34 & 182 & 27.87 & 362 & 31.75 & \\
\hline & College or university & 152 & 8.48 & 49 & 7.50 & 103 & 9.04 & \\
\hline & Master or above & 42 & 2.34 & 19 & 2.91 & 23 & 2.02 & \\
\hline \multicolumn{9}{|l|}{ Number of friends } \\
\hline & None & 29 & 1.62 & 10 & 1.53 & 19 & 1.67 & \multirow[t]{4}{*}{0.052} \\
\hline & $1-2$ & 590 & 32.91 & 209 & 32.01 & 381 & 33.42 & \\
\hline & $3-5$ & 936 & 52.20 & 327 & 50.08 & 609 & 53.42 & \\
\hline & 6 or more & 238 & 13.27 & 107 & 16.39 & 131 & 11.49 & \\
\hline $\mathrm{PA}(\mathrm{mean} \pm \mathrm{SD})[\mathrm{min} /$ week] & & \multicolumn{2}{|c|}{$126.98 \pm 120.98$} & \multicolumn{2}{|c|}{$152.82 \pm 132.17$} & \multicolumn{2}{|c|}{$112.18 \pm 110.01$} & 0.000 \\
\hline $\mathrm{ST}(\mathrm{mean} \pm \mathrm{SD})[\mathrm{min} / \mathrm{day}]$ & & \multicolumn{2}{|c|}{$384.53 \pm 222.20$} & 360.1 & \pm 224.47 & 298.5 & $=219.76$ & 0.000 \\
\hline $\operatorname{SLP}($ mean \pm SD) $[\mathrm{min} /$ day $]$ & & 443.5 & \pm 91.52 & 436.3 & \pm 98.25 & 447.6 & $=87.21$ & 0.012 \\
\hline
\end{tabular}

BMI: body mass index;

MSE: muscle-strengthening exercise;

MSE guidelines: reporting at least 2 days was regarded as meeting the guidelines;

PA: physical activity;

ST: sedentary behavior;

SLP: sleep duration;

SD: standard deviation. 


\begin{tabular}{|c|c|c|c|c|c|c|c|c|}
\hline & & \multicolumn{2}{|l|}{ Total } & \multicolumn{2}{|c|}{ Male } & \multicolumn{2}{|c|}{ Female } & \multirow[t]{2}{*}{$p$ for sex difference } \\
\hline & & $\mathbf{N}$ & $\%$ & $\mathbf{n}$ & $\%$ & $\mathbf{n}$ & $\%$ & \\
\hline \multicolumn{9}{|l|}{ MSE days } \\
\hline & 0 days & 1292 & 72.06 & 379 & 58.04 & 913 & 80.09 & \multirow[t]{8}{*}{0.000} \\
\hline & 1 day & 55 & 3.07 & 31 & 4.75 & 24 & 2.11 & \\
\hline & 2 days & 104 & 5.80 & 54 & 8.27 & 50 & 4.39 & \\
\hline & 3 days & 142 & 7.92 & 73 & 11.18 & 69 & 6.05 & \\
\hline & 4 days & 77 & 4.29 & 39 & 5.97 & 38 & 3.33 & \\
\hline & 5 days & 63 & 3.51 & 39 & 5.97 & 24 & 2.11 & \\
\hline & 6 days & 25 & 1.39 & 18 & 2.76 & 7 & 0.61 & \\
\hline & 7 days & 35 & 1.95 & 20 & 3.06 & 15 & 1.32 & \\
\hline \multicolumn{9}{|l|}{ MSE guidelines } \\
\hline & Not met & 1347 & 75.13 & 410 & 62.79 & 937 & 82.19 & \multirow[t]{2}{*}{0.000} \\
\hline & Met & 446 & 24.87 & 243 & 37.21 & 203 & 17.81 & \\
\hline Depression (mean \pm SD) & & \multicolumn{2}{|c|}{$6.80 \pm 5.19$} & \multicolumn{2}{|c|}{$6.04 \pm 5.13$} & \multicolumn{2}{|c|}{$7.24 \pm 5.17$} & 0.000 \\
\hline \multicolumn{9}{|l|}{ BMI: body mass index; } \\
\hline \multicolumn{9}{|c|}{ MSE: muscle-strengthening exercise; } \\
\hline \multicolumn{9}{|c|}{ MSE guidelines: reporting at least 2 days was regarded as meeting the guidelines; } \\
\hline \multicolumn{9}{|l|}{ PA: physical activity; } \\
\hline \multicolumn{9}{|l|}{ ST: sedentary behavior; } \\
\hline \multicolumn{9}{|l|}{ SLP: sleep duration; } \\
\hline SD: standard deviation. & & & & & & & & \\
\hline
\end{tabular}


Table 2

Correlation matric among the variables included in this study (for MSE days)

\begin{tabular}{|c|c|c|c|c|c|c|c|c|c|c|c|c|c|c|}
\hline & 1 & 2 & 3 & 4 & 5 & 6 & 7 & 8 & 9 & 10 & 11 & 12 & 13 & 14 \\
\hline 1 & 1 & & & & & & & & & & & & & \\
\hline 2 & -0.04 & 1 & & & & & & & & & & & & \\
\hline 3 & -0.31 ** & $0.09 * \star \star$ & 1 & & & & & & & & & & & \\
\hline 4 & $0.13^{\star \star \star}$ & 0.003 & $-0.15^{\star \star \star}$ & 1 & & & & & & & & & & \\
\hline 5 & $-0.06^{*}$ & 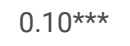 & 0.02 & 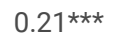 & 1 & & & & & & & & & \\
\hline 6 & $0.12^{\star \star \star}$ & $-0.10 * \star \star *$ & -0.04 & -0.04 & $-0.19 * \star \star$ & 1 & & & & & & & & \\
\hline 7 & 0.01 & 0.02 & 0.03 & $-0.09 \star \star \star *$ & -0.04 & $-0.11^{\star \star \star}$ & 1 & & & & & & & \\
\hline 8 & 0.03 & $-0.13^{\star \star *}$ & 0.03 & $-0.26^{\star \star \star}$ & $-0.33^{\star \star \star}$ & 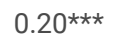 & 0.01 & 1 & & & & & & \\
\hline 9 & 0.03 & $-0.18 * \star \star$ & 0.03 & $-0.31 \star \star \star *$ & $-0.33^{\star \star *}$ & 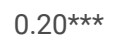 & 0.03 & $0.61^{\star \star \star}$ & 1 & & & & & \\
\hline 10 & -0.05 & 0.004 & -0.001 & $-0.05^{\star}$ & -0.03 & $0.09 * \star \star$ & -0.002 & 0.02 & $0.07 * \star$ & 1 & & & & \\
\hline 11 & $-0.16^{\star \star \star}$ & -0.05 & $0.11^{\star \star \star}$ & $-0.06^{*}$ & $-0.05^{\star}$ & $0.09 * \star \star$ & -0.01 & 0.04 & 0.06 ** & $0.06^{*}$ & 1 & & & \\
\hline 12 & $0.08^{* \star \star}$ & 0.005 & $-0.06^{\star}$ & -0.02 & -0.06 ** & -0.02 & -0.05 & $0.05^{\star}$ & 0.04 & -0.004 & $-0.18 \star \star \star *$ & 1 & & \\
\hline 13 & $0.06 *$ & $-0.08^{* * *}$ & $-0.07 \star \star$ & -0.002 & -0.02 & $0.06^{* *}$ & 0.02 & -0.01 & 0.02 & 0.04 & 0.02 & $0.06^{*}$ & 1 & \\
\hline 14 & $-0.22^{\star \star \star}$ & 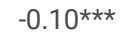 & $0.11^{\star \star \star}$ & $-0.12^{\star \star \star}$ & -0.06 ** & $0.05^{\star}$ & -0.01 & $0.08^{* *}$ & $0.12^{\star \star \star}$ & $0.05^{\star}$ & $0.27 * \star \star$ & $-0.11^{\star \star *}$ & -0.04 & 1 \\
\hline 15 & $0.11^{\star \star \star}$ & 0.000 & $-0.05^{\star}$ & $0.07^{\star *}$ & -0.01 & $-0.14^{\star \star \star}$ & $0.06^{\star}$ & 0.01 & -0.02 & 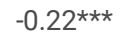 & $-0.12^{\star \star \star}$ & $0.14^{\star \star \star}$ & $-0.13^{\star \star \star}$ & $-0.11^{\prime}$ \\
\hline \multicolumn{15}{|c|}{${ }^{*} p<0.05$} \\
\hline \multicolumn{15}{|c|}{$\star \star p<0.01$} \\
\hline \multicolumn{15}{|c|}{$\star \star \star ~ p<0.001$} \\
\hline \multicolumn{15}{|c|}{ 1: Sex } \\
\hline \multicolumn{15}{|c|}{ 2: Age } \\
\hline \multicolumn{15}{|c|}{ 3: BMI } \\
\hline \multicolumn{15}{|c|}{ 4: Siblings } \\
\hline \multicolumn{15}{|c|}{ 5: Residence } \\
\hline \multicolumn{15}{|c|}{ 6: Family structure } \\
\hline \multicolumn{15}{|c|}{ 7: Perceived family affluence } \\
\hline \multicolumn{15}{|c|}{ 8: Father education level } \\
\hline \multicolumn{15}{|c|}{ 9: Mother education level } \\
\hline \multicolumn{15}{|c|}{ 10: Number of friends } \\
\hline \multicolumn{15}{|c|}{ 11: PA } \\
\hline \multicolumn{15}{|c|}{ 12: ST } \\
\hline \multicolumn{15}{|c|}{ 13: SLP } \\
\hline \multicolumn{15}{|c|}{ 14: MSE days } \\
\hline \multicolumn{15}{|c|}{ 15: Depression } \\
\hline \multicolumn{15}{|c|}{ PA: physical activity } \\
\hline \multicolumn{15}{|c|}{ ST: sedentary time } \\
\hline \multicolumn{15}{|c|}{ SLP: sleep duration } \\
\hline MS & : muscle-st & ngthenin & exercise & & & & & & & & & & & \\
\hline
\end{tabular}


Table 3

Correlation matrix among the variables included in this study (for MSE guidelines)

\begin{tabular}{|c|c|c|c|c|c|c|c|c|c|c|c|c|c|c|}
\hline & 1 & 2 & 3 & 4 & 5 & 6 & 7 & 8 & 9 & 10 & 11 & 12 & 13 & 14 \\
\hline 1 & 1 & & & & & & & & & & & & & \\
\hline 2 & -0.04 & 1 & & & & & & & & & & & & \\
\hline 3 & $-0.31 * \star \star$ & $0.09 * * *$ & 1 & & & & & & & & & & & \\
\hline 4 & $0.13^{\star \star \star}$ & 0.003 & $-0.15^{\star \star \star}$ & 1 & & & & & & & & & & \\
\hline 5 & $-0.06 *$ & $0.09 \star \star \star$ & 0.02 & 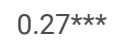 & 1 & & & & & & & & & \\
\hline 6 & $0.12^{\star \star \star}$ & $-0.10 \star \star \star$ & -0.04 & -0.04 & $-0.19 * * *$ & 1 & & & & & & & & \\
\hline 7 & 0.01 & 0.02 & 0.03 & $-0.09 \star \star \star$ & -0.04 & 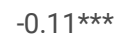 & 1 & & & & & & & \\
\hline 8 & 0.03 & $-0.13^{\star \star}$ & 0.03 & $-0.26^{\star \star \star}$ & $-0.33^{\star * \star}$ & 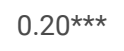 & 0.01 & 1 & & & & & & \\
\hline 9 & 0.03 & $-0.18^{\star \star \star}$ & 0.03 & $-0.31^{\star \star \star}$ & $-0.33^{\star \star \star}$ & $0.20^{\star \star \star}$ & 0.03 & $0.61^{\star \star \star}$ & 1 & & & & & \\
\hline 10 & -0.05 & 0.004 & -0.001 & $-0.05^{\star}$ & -0.03 & 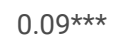 & -0.002 & 0.02 & $0.07 *$ & 1 & & & & \\
\hline 11 & $-0.16^{\star \star \star}$ & -0.05 & $0.11^{\star \star \star}$ & $-0.06 *$ & $-0.05^{\star}$ & $0.09 * * \star$ & -0.01 & 0.04 & $0.06^{\star \star}$ & $0.06 *$ & 1 & & & \\
\hline 12 & $0.09 * \star \star$ & 0.01 & $-0.06^{\star}$ & -0.02 & -0.06 ** & -0.02 & -0.05 & $0.05^{\star}$ & 0.04 & -0.004 & $-0.18^{\star \star \star}$ & 1 & & \\
\hline 13 & $0.06^{*}$ & $-0.08^{\star \star \star}$ & $-0.07 * \star$ & -0.002 & -0.02 & $0.06^{* *}$ & 0.02 & -0.01 & 0.02 & 0.04 & 0.02 & $0.06^{*}$ & 1 & \\
\hline 14 & $-0.22^{\star \star \star}$ & $-0.08 * \star$ & $0.10 \star \star \star$ & $-0.11^{\star \star \star}$ & $-0.06^{\star}$ & 0.03 & 0.002 & $0.06^{*}$ & $0.10^{\star \star * \star}$ & $0.05^{\star}$ & $0.28 * \star \star$ & $0.12^{\star \star \star}$ & -0.01 & 1 \\
\hline 15 & $0.11^{\star \star \star}$ & 0.0004 & $-0.05^{\star}$ & $0.07^{* *}$ & -0.01 & -0.14 *** & $0.06^{*}$ & 0.01 & -0.02 & $-0.22^{* \star *}$ & $-0.12^{\star \star \star}$ & $0.14^{\star \star \star}$ & $0.13^{\star * \star}$ & $-0.11^{\star x}$ \\
\hline \multicolumn{15}{|c|}{$* p<0.05$} \\
\hline \multicolumn{15}{|c|}{$\star \star p<0.01$} \\
\hline \multicolumn{15}{|c|}{$\star \star \star * p<0.001$} \\
\hline \multicolumn{15}{|c|}{ 1: Sex } \\
\hline \multicolumn{15}{|c|}{ 2: Age } \\
\hline \multicolumn{15}{|c|}{ 3: BMI } \\
\hline \multicolumn{15}{|c|}{ 4: Siblings } \\
\hline \multicolumn{15}{|c|}{ 5: Residence } \\
\hline \multicolumn{15}{|c|}{ 6: Family structure } \\
\hline \multicolumn{15}{|c|}{ 7: Perceived family affluence } \\
\hline \multicolumn{15}{|c|}{ 8: Father education level } \\
\hline \multicolumn{15}{|c|}{ 9: Mother education level } \\
\hline \multicolumn{15}{|c|}{ 10: Number of friends } \\
\hline \multicolumn{15}{|c|}{ 11: PA } \\
\hline \multicolumn{15}{|c|}{ 12: ST } \\
\hline \multicolumn{15}{|c|}{ 13: SLP } \\
\hline \multicolumn{15}{|c|}{ 14: MSE days } \\
\hline \multicolumn{15}{|c|}{ 15: Depression } \\
\hline \multicolumn{15}{|c|}{ PA: physical activity; } \\
\hline \multicolumn{15}{|c|}{ ST: sedentary time; } \\
\hline \multicolumn{15}{|c|}{ SLP: sleep duration; } \\
\hline & muscle- & atheni & rercic & & . reno & t) & ve & & & & & & & \\
\hline
\end{tabular}


Table 4

Multilevel regression model results between MSE days and depression

\begin{tabular}{|c|c|c|c|c|c|}
\hline & & Beta & $95 \% \mathrm{Cl}$ & & $\begin{array}{l}p \\
\text { value }\end{array}$ \\
\hline Intercept & & 13.55 & 9.32 & 17.78 & 0.000 \\
\hline \multicolumn{6}{|l|}{ Sex } \\
\hline & Male & -0.86 & -1.38 & -0.35 & 0.001 \\
\hline & Female & Ref & & & \\
\hline \multicolumn{6}{|l|}{ Siblings } \\
\hline & Single & -0.45 & -0.97 & 0.08 & 0.099 \\
\hline & Two or more & Ref & & & \\
\hline \multicolumn{6}{|l|}{ Residence } \\
\hline & Urban & 0.26 & -2.92 & 0.81 & 0.356 \\
\hline & Rural & Ref & & & \\
\hline \multicolumn{6}{|l|}{ Family structure } \\
\hline & Full & -2.18 & -3.42 & -0.94 & 0.001 \\
\hline & Divorced & -2.56 & -4.08 & -1.03 & 0.001 \\
\hline & Other & Ref & & & \\
\hline \multicolumn{6}{|l|}{$\begin{array}{l}\text { Father education } \\
\text { level }\end{array}$} \\
\hline & $\begin{array}{l}\text { Middle school } \\
\text { or below }\end{array}$ & -0.15 & -1.63 & 1.34 & 0.847 \\
\hline & High school & 0.09 & -1.36 & 1.55 & 0.903 \\
\hline & $\begin{array}{l}\text { College or } \\
\text { university }\end{array}$ & 0.28 & -1.21 & 1.77 & 0.714 \\
\hline & $\begin{array}{l}\text { Master or } \\
\text { above }\end{array}$ & Ref & & & \\
\hline \multicolumn{6}{|l|}{$\begin{array}{l}\text { Mother } \\
\text { education level }\end{array}$} \\
\hline & $\begin{array}{l}\text { Middle school } \\
\text { or below }\end{array}$ & 0.18 & -1.63 & 1.98 & 0.848 \\
\hline & High school & 0.21 & -1.56 & 1.98 & 0.815 \\
\hline & $\begin{array}{l}\text { College or } \\
\text { university }\end{array}$ & 0.30 & -1.56 & 2.16 & 0.749 \\
\hline & $\begin{array}{l}\text { Master or } \\
\text { above }\end{array}$ & Ref & & & \\
\hline \multicolumn{6}{|l|}{$\begin{array}{l}\text { Number of } \\
\text { friends }\end{array}$} \\
\hline & None & 6.66 & 4.77 & 8.55 & 0.000 \\
\hline & $1-2$ & 2.52 & 1.78 & 3.26 & 0.000 \\
\hline & $3-5$ & 1.20 & 0.50 & 1.90 & 0.001 \\
\hline & 6 or more & Ref & & & \\
\hline Age & & -0.06 & -0.20 & 0.09 & 0.427 \\
\hline $\begin{array}{l}\text { Perceived family } \\
\text { affluence }\end{array}$ & & -0.35 & -0.50 & -0.21 & 0.000 \\
\hline
\end{tabular}

BMI: body mass index;

PA: physical activity;

ST: sedentary time;

SLP: sleep time;

MSE: muscle-strengthening exercise. 


\begin{tabular}{|lllll|}
\hline & Beta & $95 \%$ Cl & & $\begin{array}{c}\text { v } \\
\text { value }\end{array}$ \\
\hline BMI & -0.01 & -0.10 & 0.07 & 0.805 \\
\hline PA & -0.001 & -0.004 & 0.0002 & 0.085 \\
\hline ST & 0.002 & 0.002 & 0.003 & 0.000 \\
\hline SLP & -0.01 & -0.01 & -0.005 & 0.000 \\
\hline $\begin{array}{l}\text { MSE days (0-7 } \\
\text { days) }\end{array}$ & -0.17 & -0.31 & -0.03 & 0.015 \\
\hline $\begin{array}{l}\text { BMI: body mass index; } \\
\text { PA: physical activity; }\end{array}$ & & & & \\
ST: sedentary time; & & & & \\
SLP: sleep time; & & & & \\
MSE: muscle-strengthening exercise. & & & & \\
\hline
\end{tabular}


Table 5

The association between MSE guidelines and depression by multilevel regression model.

\begin{tabular}{|c|c|c|c|c|c|}
\hline & & Beta & $95 \% \mathrm{Cl}$ & & $p$ value \\
\hline Intercept & & 12.75 & 8.52 & 16.97 & 0.000 \\
\hline \multicolumn{6}{|l|}{ Sex } \\
\hline & Male & -0.88 & -1.39 & -0.36 & 0.001 \\
\hline & Female & Ref & & & \\
\hline \multicolumn{6}{|l|}{ Siblings } \\
\hline & Single & -0.46 & -0.99 & 0.07 & 0.089 \\
\hline & Two or more & Ref & & & \\
\hline \multicolumn{6}{|l|}{ Residence } \\
\hline & Urban & 0.26 & -0.29 & 0.82 & 0.353 \\
\hline & Rural & Ref & & & \\
\hline \multicolumn{6}{|l|}{ Family structure } \\
\hline & Full & -2.18 & -3.42 & -0.94 & 0.001 \\
\hline & Divorced & -2.53 & -4.06 & -1.01 & 0.001 \\
\hline & Other & Ref & & & \\
\hline \multicolumn{6}{|l|}{ Father education level } \\
\hline & Middle school or below & -0.17 & -1.65 & 1.32 & 0.825 \\
\hline & High school & 0.07 & -1.39 & 1.53 & 0.924 \\
\hline & College or university & 0.24 & -1.25 & 1.73 & 0.756 \\
\hline & Master or above & Ref & & & \\
\hline \multicolumn{6}{|l|}{ Mother education level } \\
\hline & Middle school or below & 0.26 & -1.54 & 2.06 & 0.777 \\
\hline & High school & 0.31 & -1.46 & 2.07 & 0.734 \\
\hline & College or university & 0.41 & -1.45 & 2.26 & 0.666 \\
\hline & Master or above & Ref & & & \\
\hline \multicolumn{6}{|l|}{ Number of friends } \\
\hline & None & 6.59 & 4.70 & 8.48 & 0.000 \\
\hline & $1-2$ & 2.53 & 1.79 & 3.27 & 0.000 \\
\hline & $3-5$ & 1.20 & 0.50 & 1.90 & 0.001 \\
\hline & 6 or more & Ref & & & \\
\hline Age & & -0.05 & -0.20 & 0.09 & 0.467 \\
\hline Perceived family affluence & & -0.36 & -0.50 & -0.21 & 0.000 \\
\hline BMI & & -0.01 & -0.10 & 0.07 & 0.785 \\
\hline PA & & -0.002 & 0.00 & 0.00 & 0.084 \\
\hline ST & & 0.002 & 0.00 & 0.00 & 0.000 \\
\hline SLP & & -0.01 & -0.01 & 0.00 & 0.000 \\
\hline
\end{tabular}

BMI: body mass index;

PA: physical activity;

ST: sedentary time;

SLP: sleep time;

MSE: muscle-strengthening exercise (MSE guidelines: reporting at least 2 days was regarded as meeting the guidelines). 


\begin{tabular}{|c|c|c|c|c|c|}
\hline & & Beta & $95 \%$ & & $p$ value \\
\hline & Not meeting & 0.63 & 0.07 & 1.19 & 0.027 \\
\hline & Meeting & Ref & & & \\
\hline \multicolumn{6}{|c|}{ BMI: body mass index; } \\
\hline \multicolumn{6}{|l|}{ PA: physical activity; } \\
\hline \multicolumn{6}{|l|}{ ST: sedentary time; } \\
\hline \multicolumn{6}{|l|}{ SLP: sleep time; } \\
\hline MSE: muscle-strengt & SE guidelines & days & egarde & meetin & guidelines \\
\hline
\end{tabular}

Page 15/15 